\title{
Pheromone Binding to General Odorant-binding Proteins from the Navel Orangeworm
}

\author{
Zhao Liu • Diogo M. Vidal • Zainulabeuddin Syed • \\ Yuko Ishida • Walter S. Leal
}

Received: 27 April 2010/Revised: 27 May 2010/Accepted: 31 May 2010/Published online: 10 June 2010

(C) The Author(s) 2010. This article is published with open access at Springerlink.com

\begin{abstract}
General odorant-binding proteins (GOBPs) of moths are postulated to be involved in the reception of semiochemicals other than sex pheromones, the so-called "general odorants." We have expressed two GOBPs, AtraGOBP1 and AtraGOBP2, which were previously isolated from the antennae of the navel orangeworm, Amyelois transitella. Surprisingly, these two proteins did not bind compounds that are known to attract adult moths, particularly females. The proper folding and functionality of the recombinant proteins was inferred from circular dichroism analysis and demonstration that both GOBPs bound nonanal in a pH-dependent manner. EAG experiments demonstrated that female attractants (1-phenylethanol, propionic acid phenyl ester, and isobutyric acid phenyl ester) are detected with high sensitivity by the antennae of day- 0 to day- 4 adult females, with response declining in older moths. The same age-dependence was shown for male antennae responding to constituents of the sex pheromone. Interestingly, AtraGOBP2 bound the major constituent of the sex pheromone, Z11Z13-16Ald, with affinity comparable to that shown by a pheromone-binding protein, AtraPBP1. The related alcohol bound to AtraPBP1 with higher affinity than to AtraGOBP2. AtraGOBP1 bound both ligands with low but nearly the same affinity.
\end{abstract}

Key Words Amyelois transitella $\cdot$ AtraGOBP1 . AtraGOBP2 - AtraPBP1 - Circular dichroism . Electroantennogram recording $\cdot$ Female attractants . General odorant-binding proteins $\cdot$ Protein expression

Z. Liu • D. M. Vidal · Z. Syed · Y. Ishida $\cdot$ W. S. Leal $(\square)$ Department of Entomology, University of California-Davis, 1 Shields Ave,

Davis, CA 95616, USA

e-mail: wsleal@ucdavis.edu

\section{Introduction}

There is growing evidence in the literature suggesting that odorant-binding proteins (OBPs) are involved in the early events of odorant reception in insects. OBPs were first isolated from moth antennae (Vogt and Riddiford 1981), but they have now been identified from insects in all orders hitherto investigated [for a recent example, see (Gong et al. 2009a)]. RNA interference experiments in the southern house mosquito, Culex quinquefasciatus (Pelletier et al. 2010), and the malaria mosquito, Anopheles gambiae (Biessmann et al. 2010), showed that reduction in OBP expression leads to lower sensitivity for the detection of specific odorants, whereas a model has been proposed for the fruit fly, Drosophila melanogaster, in which an OBP, LUSH, activates the receptor while bound to a pheromone ligand (Laughlin et al. 2008). In contrast, moth pheromone receptors are activated directly by ligands, as demonstrated by expressing receptors in a heterologous system devoid of OBPs and stimulating with pheromones (Nakagawa et al. 2005). Previously, we demonstrated that an OBP from the silkworm moth, Bombyx mori, BmorPBP1, enhances sensitivity when the moth receptor BmorOR1 is expressed in the empty neuron system of the fruit fly (Syed et al. 2006).

The existence of at least two groups of OBPs became apparent when the first ones were isolated from moth species. Pheromone-binding proteins (PBPs), postulated to be functionally involved in pheromone reception, are enriched or expressed only in male antennae, and show poor conserved sequences between species (Vogt et al. 1991). In contrast, some highly conserved antennal proteins show expression in both males and females, thus suggesting that they are involved in the reception of "general" odorants (i.e., odorants other than pheromones) and, consequently, 
they were dubbed general-odorant binding proteins (GOBPs) (Vogt et al. 1991). Immunocytochemical studies have further substantiated this hypothesis. PBPs have been expressed in the pheromone-detecting, long trichoid sensilla in the male antennae of the silkworm moth, B. mori, and the wild silkworm moth, Antheraea polyphemus (Steinbrecht et al. 1995). In contrast, GOBPs have been shown to be expressed in basiconic sensilla, which are sensitive to plant-derived compounds and other "general" odorants (Steinbrecht et al. 1995). Exceptionally, a GOBP from Mamestra brassicae, MbraGOBP2, has been expressed in long trichoid sensilla and has high affinity for a behavioral antagonist detected by neurons housed in these sensilla (Jacquin-Joly et al. 2000). Additionally, it has been shown that a female pheromone constituent of $A$. polyphemus binds to a GOBP expressed in male and female antenna (Ziegelberger 1995). In contrast to PBPs from B. mori, BmorGOBP2 was recently shown to bind bombykol, but not bombykal, thus suggesting a possible role in pheromone reception (Zhou et al. 2009).

Recently, we isolated and cloned the cDNAs that encode various olfactory proteins from the navel orangeworm, Amyelois transitella (Walker) (Lepidoptera: Pyralidae), a major pest of almonds, pistachios, and walnuts (Leal et al. 2009). Considering that two proteins, AtraGOBP1 and AtraGOBP2, were enriched in female antennae, we hypothesized that they may be involved in the reception of female attractants. Here, we report that recombinant AtraGOBP1 and AtraGOBP2 did not bind semiochemicals known to attract adult moths, particularly females, i.e., 1phenylethanol, propionic acid phenyl ester (hereafter referred to as PAPE = phenyl propionate), and isobutyric acid phenyl ester (hereafter referred to as IBAPE = phenyl 2-methylpropionate) (Price et al. 1967), but rather showed higher affinity to nonanal, a component of the head space volatile from almonds (Beck et al. 2009). Electroantennogram (EAG) studies showed that all these semiochemicals are detected by the antennae, so reception of female attractants may involve other yet unknown OBPs. Interestingly, both AtraGOBP1 and AtraGOBP2 bound to and discriminate two constituents of the A. transitella sex pheromone (Leal et al. 2005b), suggesting a possible role in pheromone reception.

\section{Methods and Materials}

Protein Expression and Purification Each cDNA fragment was amplified by PCR with gene-specific primers and PfuUltra HotStart DNA polymerase (Stratagene, La Jolla, CA, USA) as Taq DNA polymerase, gel-purified by using QIAquick Gel Extraction Kit (Qiagen, Valencia, CA, USA), and subcloned into the recognition site of Eco RV in
pBluescript SK (+) (Stratagene) as previously described (Leal et al. 2009). Each insert DNA was used as template for PCR-based insertion of recognition sites of restriction enzymes. The following primers were designed for the PCR: 5-KpnI-AtraGOBP1，5'-CCGGGGTACCCGAC GTGGCCGTCATGAAGG-3'; 3-BamHI-AtraGOBP1, 5'GCGCGGATCCTTATGTCTCGGCCTCCATGA-3'; 5HaeIII-AtraGOBP2，5'-TTTGCGGCCAGTGCTGAGG TGATGAGCCAT-3'; 3-XhoI-AtraGOBP2, 5' CCGCTCGAGTCAATATTTCTCCATGACTG-3'. After incubation at $95^{\circ} \mathrm{C}$ for $2 \mathrm{~min}$, we initiated forty cycles of stepwise PCR with the following amplification program $\left(95^{\circ} \mathrm{C}\right.$ for $30 \mathrm{sec}, 40^{\circ} \mathrm{C}$ for $30 \mathrm{sec}$, and $72^{\circ} \mathrm{C}$ for $1 \mathrm{~min}$ ). One microgram of pET-22b(+) plasmid DNA (Novagen, Gibbstown, NJ, USA) was double-digested with Msc I and Bam HI or Xho I (New England Biolabs, Ipswich, MA, USA), and gel-purified.

For preparation of pET-22b-AtraGOBP1, $1 \mu \mathrm{g}$ of the PCR product amplified by $5-\mathrm{KpnI}-\mathrm{AtraGOBP} 1$ and 3BamHI-AtraGOBP1 was treated with Kpn I (New England Biolabs) and subsequently re-purified by QIAquick PCR Purification Kit (Qiagen). Purified DNA was treated with T4 DNA polymerase (New England Biolabs) at $12^{\circ} \mathrm{C}$ for $20 \mathrm{~min}$ to remove $5^{\prime}$-protruding single strand DNA fragment. After re-purification of DNA by QIAquick PCR Purification Kit (Qiagen), DNA was digested with Bam HI. Five hundred bp of DNA fragment were gel-purified and ligated into pET-22b (+) digested previously. Construction of the vector was confirmed by sequencing.

For construction of pET-22b-AtraGOBP2, the PCR product amplified by 5 -HaeIII-AtraGOBP2 and 3-XhoIAtraGOBP2 was purified by QIAquick PCR purification kit and double-digested with Hae III and Xho I. The treated DNA fragment was gel-purified and ligated into pET-22b $(+)$ vector as described above.

Expression was performed in LB medium with transformed BL21(DE3) cells (Novagen) following a previously reported protocol (Leal et al. 2009). Proteins in the periplasmic fraction were extracted with $10 \mathrm{mM}$ Tris $\cdot \mathrm{HCl}$ (pH 8) by using three cycles of freeze-and-thaw and centrifuging at $16,000 \times g$ to remove debris. The supernatant was collected and loaded on HiPrep DEAE FF column (GE Healthcare Biosciences, Piscataway, NJ, USA). Unless stated otherwise, all separations by ion-exchange chromatography were done with a linear gradient of $0-500 \mathrm{mM}$ $\mathrm{NaCl}$ in $10 \mathrm{mM}$ Tris $\mathrm{HCl}(\mathrm{pH})$. Fractions containing the target proteins were further purified on HiPrep Q FF column (GE Healthcare Biosciences) and, subsequently, on Mono Q 10/100 GL column (GE Healthcare Biosciences). These fractions containing target proteins were concentrated by centrifuging in Centriprep YM-10 (Millipore, Billerica, MA, USA) at $3000 \times g$ until sample volume was less than $5 \mathrm{ml}$. Then, the sample was loaded on HiLoad 26/60 


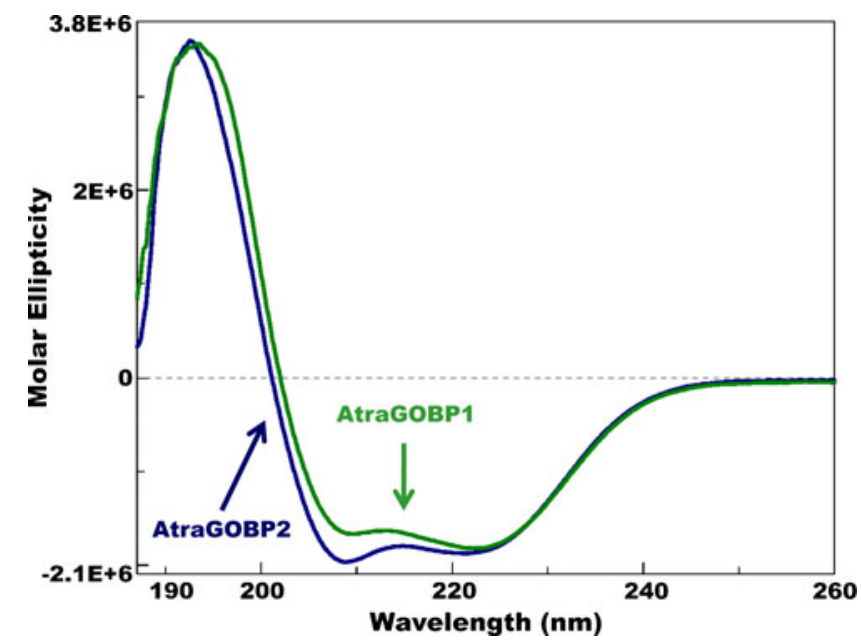

Fig. 1 Far-UV-CD spectra of two general-odorant binding proteins from the navel orangeworm, Amyelois transitella. AtraGOBP1, green trace; AtraGOBP2, blue trace. Note the lowest minima for AtraGOBP2 and AtraGOBP1 appeared at $209 \mathrm{~nm}$ and $223 \mathrm{~nm}$, respectively

Superdex-75pg gel-filtration column (GE Healthcare Biosciences) preequilibrated with $150 \mathrm{mM} \mathrm{NaCl}$ and $20 \mathrm{mM}$ Tris $\cdot \mathrm{HCl}(\mathrm{pH}$ 8). Fractions were analyzed by SDSPAGE and LC-MS. LC-ESI-MS was performed with a LCMS-2010 (Shimadzu, Kyoto, Japan). HPLC separations were done on Zorbax 300SB-C8 Narrow Bore column $(100 \times 2.1 \mathrm{~mm} ; 5 \mu \mathrm{m}$; Agilent Technologies, Palo Alto, CA, USA) with a gradient of water and acetonitrile plus $2 \%$ acetic acid as a modifier. The detector was operated with the nebulizer gas flow at $1.0 \mathrm{1} / \mathrm{min}$ and the curved desolvation line and heat block at $250^{\circ} \mathrm{C}$. Fractions containing traces of nontarget proteins were purified further by Mono-Q column with a shallower gradient buffer. Highly purified protein fractions were concentrated by Centriprep YM10, desalted on HiPrep 26/10 desalting column (GE Healthcare Biosciences) with water as mobile phase, analyzed by LC-ESI/MS, lyophilized, and stored at $-80^{\circ}$ $\mathrm{C}$ until use. The concentrations of AtraGOBPs were measured by UV radiation at $280 \mathrm{~nm}$ in $20 \mathrm{mM}$ sodium phosphate $(\mathrm{pH} 6.5)$ and $6 \mathrm{M}$ guanidine $\mathrm{HCl}$ by using the theoretical extinction coefficients calculated with expasy software (http://us.expasy.org/tools/protparam.html). AtraPBP1 was prepared as previously reported (Leal et al. 2009). Circular dichroism (CD) spectra were recorded by using a J-810 spectropolarimeter (Jasco, Easton, MD, USA) with $0.2 \mathrm{mg} / \mathrm{ml}$ AtraGOBPs in either $20 \mathrm{mM}$ ammonium acetate, $\mathrm{pH} 7$ or $20 \mathrm{mM}$ sodium acetate, pH 5.

Binding Assays Binding was measured by incubating AtraGOBPs or AtraPBP1 with test ligands, separating unbound and bound protein, extracting ligand from the latter sample, and analyzing by gas chromatography, according to a previously reported "cold binding assay" (Leal et al. 2005a). After lowering pH to release the ligand, bound protein fractions were extracted and analyzed by gas chromatography with flame ionization detection (GC-FID) for quantification and by GC-mass spectrometry (GC-MS) for confirmation of ligand identity. GC-FID and GC-MS were performed with a 6890 series GC and a 5973 Network Mass Selective Detector (Agilent Technologies), respectively. Both instruments were equipped with the same type of capillary column (HP-5MS, $25 \mathrm{~m} \times 0.25 \mathrm{~mm}$; $0.25 \mu \mathrm{m}$; Agilent Technologies) operated under the same temperature program. For female attractants of low molecular weight, the oven was operated at $50^{\circ} \mathrm{C}$ for $1 \mathrm{~min}$, increased to $180^{\circ} \mathrm{C}$ at a rate of $10^{\circ} \mathrm{C} / \mathrm{min}$, and held at the final temperature for $5 \mathrm{~min}$, whereas for pheromones the
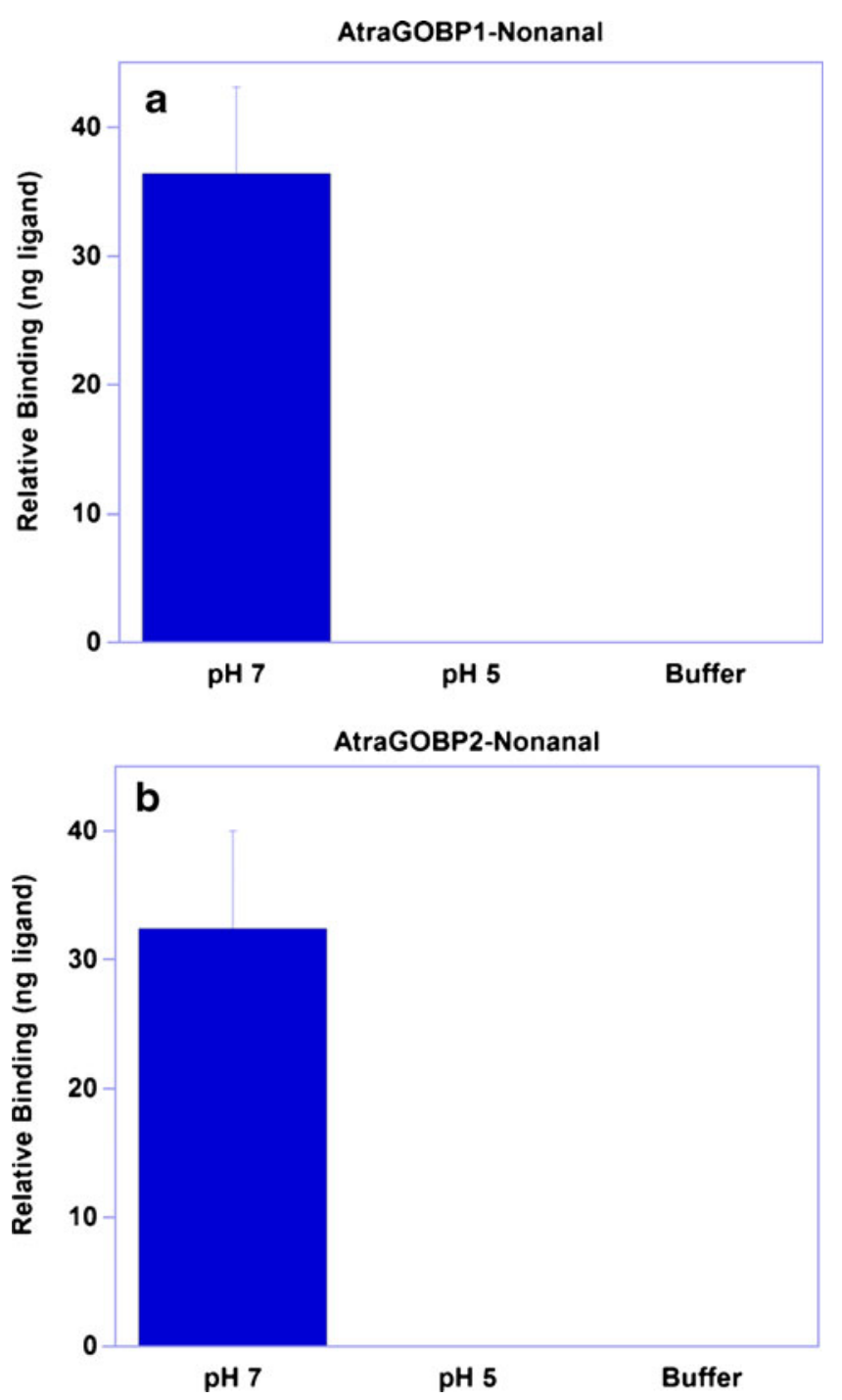

Fig. 2 Binding of nonanal to Amyelois transitella AtraGOBPs. This aldehyde showed high affinity to AtraGOBP1 (a) and AtraGOBP2 (b) at high $\mathrm{pH}$, but no affinity at low $\mathrm{pH}$. No traces of the ligand were detected in the buffer at $\mathrm{pH} 7$. Histogram bars represent mean+SEM $(N=5)$ 
temperature program began at $70^{\circ} \mathrm{C}$ for $1 \mathrm{~min}$, increased to $250^{\circ} \mathrm{C}$ at a rate of $10^{\circ} \mathrm{C} / \mathrm{min}$, and held at the final temperature for $10 \mathrm{~min}$. Additionally, binding was measured by a competitive binding assay with $\mathrm{N}$-phenyl-1-naphthylamine (NPN) as a fluorescent reporter (Ban et al. 2002). Fluorescence spectra were recorded on a Shimadzu RF-5301 PC spectrofluorometer.

Insects Details of $A$. transitella rearing have been previously described (Parra-Pedrazzoli and Leal 2006). Briefly, larvae were raised on roasted pistachio in growth chambers (Percival Scientific, Perry, IA, USA) under $28 \pm 2{ }^{\circ} \mathrm{C}$ temperature, $75 \pm 10 \%$ relative humidity $(\mathrm{RH})$, and a $16: 8 \mathrm{~h}$ (light:dark) photo regime. Emerging moths were collected daily, separated by sex, and transferred to plastic boxes $(12 \times 12 \times 5 \mathrm{~cm} ; 669 \mathrm{ml}$ lunchbox, TakeAlong containers,
Rubbermaid, Fairlawn, OH, USA) provided with up to ten layers of water soaked paper towels (Thirsty Ultra Absorbent, $27.9 \times 27.9 \mathrm{~cm}$; Safeway, Phoenix, AZ, USA). Box covers were perforated to allow air circulation. This arrangement provided $\sim 100 \% \mathrm{RH}$.

Electroantennogram (EAG) Recordings We developed a method wherein an adult moth is restrained in a pipette tip (200 $\mu$ l, USA Scientific Inc., Ocala, FL, USA) that was cut from the top to have a large (ca. $2 \mathrm{~mm}$ ) tip diameter. The moth was pushed gently through the base of the pipette tip with a humidified tissue paper stub until the antennae and part of the head protruded from the tip. The head was immobilized with a non-drying clay (Claytoon ${ }^{\mathrm{TM}}$, Van Aken International, CA, USA) leaving a small part of one eye and two antenna exposed. The pipette tip holding the
Fig. 3 EAG traces recorded from antennae of live female Amyelois transitella in response to PAPE, IBAPE, 1phenylethanol, and nonanal. All traces from top to bottom show the responses to control, and increasing doses of the test compounds (from 0.1 to $10 \mu \mathrm{g} / \mu \mathrm{l}$ source dose)
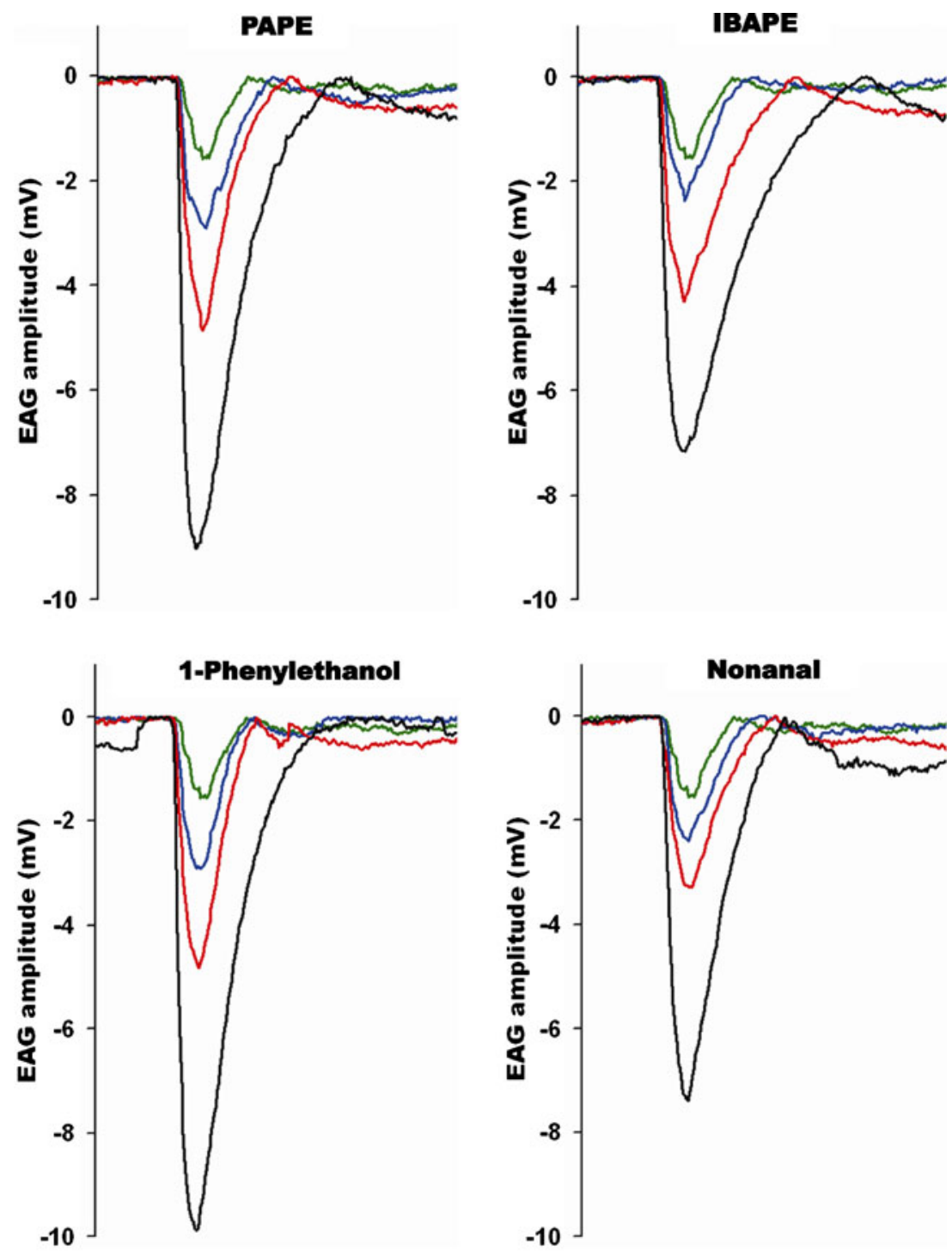

Source Dose $(\mu \mathrm{g} / \mu \mathrm{l}):=0 ;-0.1 ;-1 ;-10$ 


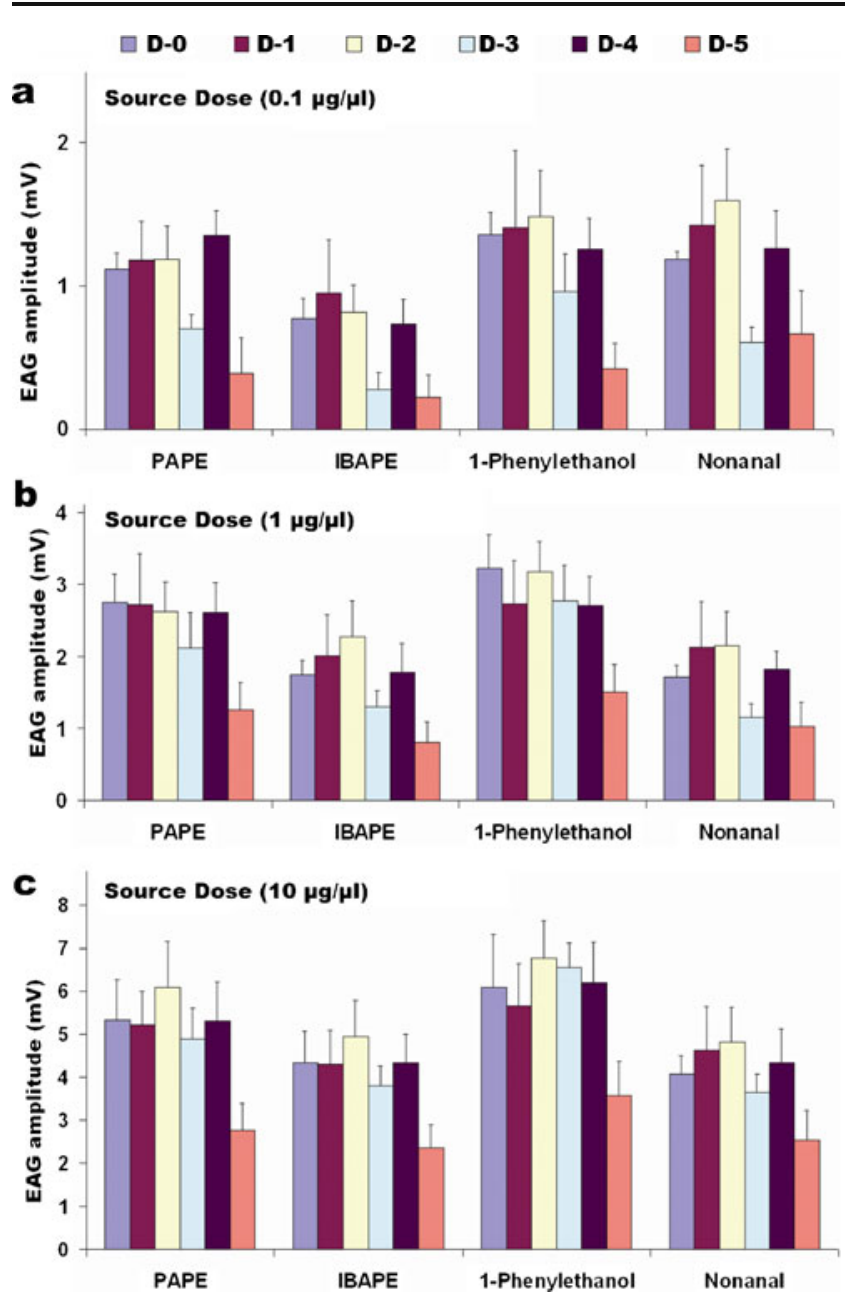

Fig. 4 Age-dependent responses of female Amyelois transitella antennae to attractants and nonanal. Responses displayed in (a), (b), and (c) were recorded with $0.1,1$, and $10 \mu \mathrm{g} / \mu \mathrm{l}$ source dose, respectively. Histogram bars represent mean + SEM $(N=10)$ restrained moth was placed on a platform of the EAG Micromanipulator MP-12 (Syntech, Kirchzarten, Germany) between the two electrode holders. A saline filled electrode impaled the exposed area of the eye under the microscope (Leica MZ75) that served as reference while the recording electrode contacted the two antennae whose distal segments were excised. Indifferent and recording electrodes were filled with $0.1 \mathrm{M} \mathrm{KCl}$ solution with $0.5 \%$ polyvinylpyrrolidone. The EAG signals were amplified, monitored, and analyzed with software EAG 2000 (Syntech). The preparation was held in a humidified air stream delivered by the Syntech stimulus controller (CS-55 model; Syntech) at $26 \mathrm{ml} / \mathrm{sec}$ to which a stimulus pulse of $4 \mathrm{ml} / \mathrm{s}$ was added for $500 \mathrm{~ms}$. Signals were recorded for $10 \mathrm{sec}$, starting $2 \mathrm{sec}$ before the onset of the stimulus pulse. The antennal preparation was stimulated with a $500 \mathrm{~ms}$ pulse during which ca. $2 \mathrm{ml}$ of the purified air from a $5 \mathrm{ml}$ polypropylene syringe containing the stimulus were added into the main air stream. Throughout this study, charcoal-filtered atmospheric air was used for the main airflow and stimulus delivery. To prevent changes in airflow during stimulation, a compensatory charcoal-filtered airflow of $2 \mathrm{ml} / \mathrm{sec}$ was delivered via another solenoid valve through a blank syringe into the glass tube, and at the same distance from the preparation. Following high responses, a gap of at least 1 min was allowed between stimulations.

Chemical Stimuli Nonanal and 1-phenylethanol (both $>90 \%$ pure) were from Fluka (St. Louis, MO, USA). Propionic acid phenyl ester (PAPE) and isobutyric acid phenyl ester (IBAPE) (both $>95 \%$ pure) were purchased from Tokyo Chemical Industry (Portland, OR, USA). (Z,Z)-11,13-Hexadecadienal (Z11Z13-16Ald), (Z,Z)-11,13hexadecadienol (Z11Z13-16OH), and (Z,Z,Z,Z,Z)3,6,9,12,15-tricosapentaene (Z3Z6Z9Z12Z15-23Hy) were
Fig. 5 Age-dependent responses of male Amyelois transitella antennae to the major constituent of the sex pheromone, Z11Z13-16Ald, and a key secondary constituent, Z3Z6Z9Z12Z15-23Hy. Histogram bars represent mean+SEM $(N=10)$ $\square$ D-0 $\square$ D-1 $\square$ D-2 $\square$ D-3 $\square$ D-4 $\square$ D-5

Source Dose (1 $\mu \mathrm{g} / \mathrm{\mu l})$

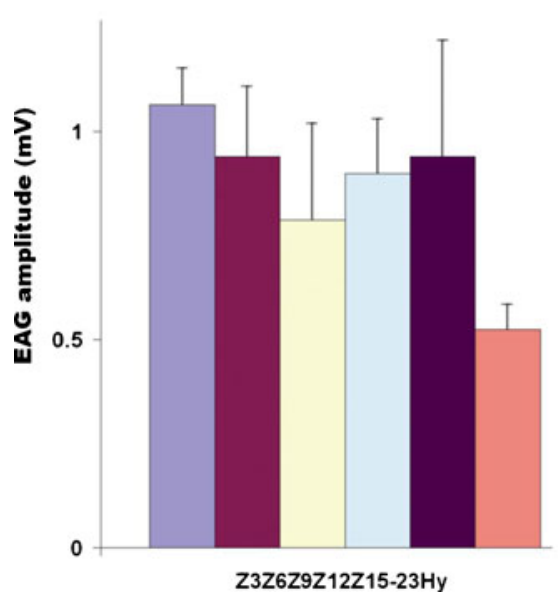


obtained from Bedoukian Research Inc. (Danbury, CT, USA). All chemicals were diluted, w/v, with hexane distilled in an all-glass apparatus to make a stock solution of $10 \mu \mathrm{g} / \mu \mathrm{l}$, and decadic dilutions were made. An aliquot $(10 \mu \mathrm{l})$ of a stimulus solution was loaded onto a filter paper strip $(8 \times 40 \mathrm{~mm})$, hexane was evaporated by gently shaking for $10 \mathrm{sec}$ under a fumehood, and the strip was placed in a $5 \mathrm{ml}$ polypropylene syringe from which various volumes were ejected. Hexane alone and an empty syringe served as negative controls.

\section{Results and Discussion}

By using a previously developed protocol for functional expression of OBPs (Wojtasek and Leal 1999), we generated recombinant samples of AtraGOBP1 and AtraGOBP2 of high purity ( $>98 \%$, by LC-MS). LC-ESI-MS analysis of AtraGOBP1 gave a molecular mass of $16,897 \mathrm{Da}$ consistent with the calculated molecular mass of 16,903 Da (Leal et al. 2009) given the formation of three disulfide bridges (expected 16,897 Da). Deconvolution of the mass spectrum from AtraGOBP2 gave a molecular mass of $16,161 \mathrm{Da}$ in close agreement with the calculated molecular mass of 16,166 Da (Leal et al. 2009) considering the formation of three disulfide linkages (expected, 16,160 Da). Far-ultraviolet (UV)-circular dichroism (CD) spectra from both proteins resembled that of the pheromone-binding protein AtraPBP1 (Leal et al. 2009), with maximum at ca. $193 \mathrm{~nm}$ and two minima at $209 \mathrm{~nm}$ and $223 \mathrm{~nm}$ (Fig. 1). Therefore, both AtraGOBP1 and AtraGOBP2 are $\alpha$-helical-rich proteins, which is a common feature of moth OBPs (Wojtasek and Leal 1999). The spectra from AtraGOBP1 and AtraGOBP2 differed slightly in the maximum and in the intensity of the first of the two minima (Fig. 1).

Because gene expression analysis suggested that AtraGOBP1 and AtraGOBP2 are highly expressed in female antennae (Leal et al. 2009), we hypothesized that these proteins might be involved in the reception of attractants. We then tested by a cold binding assay (Leal et al. 2005a) whether AtraGOBP1 and/or AtraGOBP2 would bind semiochemicals like PAPE, IBAPE, and 1-phenylethanol, which are commonly referred to as female attractants (Price et al. 1967). Surprisingly, none of these ligands bound to the test proteins, but high background levels occurred even when these ligands were incubated with a buffer solution (devoid of protein), precluding an unambiguous conclusion. We then tested competitive binding by fluorescence by using a NPN reporter (Ban et al. 2002). None of the tested ligands displaced NPN, thus confirming that PAPE, IBAPE, and 1phenylethanol do not bind to AtraGOBP1 or AtraGOBP2. To confirm that the recombinant proteins were functional, we searched the literature for other possible test compounds. Evidence that a GOBP from the Asiatic rice borer, Chilo suppressalis (Walker) (Lepidoptera: Crambidae), has high affinity for aldehydes (Gong et al. 2009b) led us to test nonanal, which has been identified in the headspace volatiles from almonds and demonstrated to stimulate antennae of female $A$. transitella in EAG studies (Beck et al. 2009). Nonanal bound with high affinity to both AtraGOBP1 (Fig. 2a) and AtraGOBP2 (Fig. 2b) at high $\mathrm{pH}$. The fact that no binding was detected at low pH (Fig. 2) suggests that both AtraGOBP1 and AtraGOBP2 undergo $\mathrm{pH}$-mediated conformational changes, as previously demonstrated for AtraPBP1 (Leal et al. 2009; Xu et al. 2010).
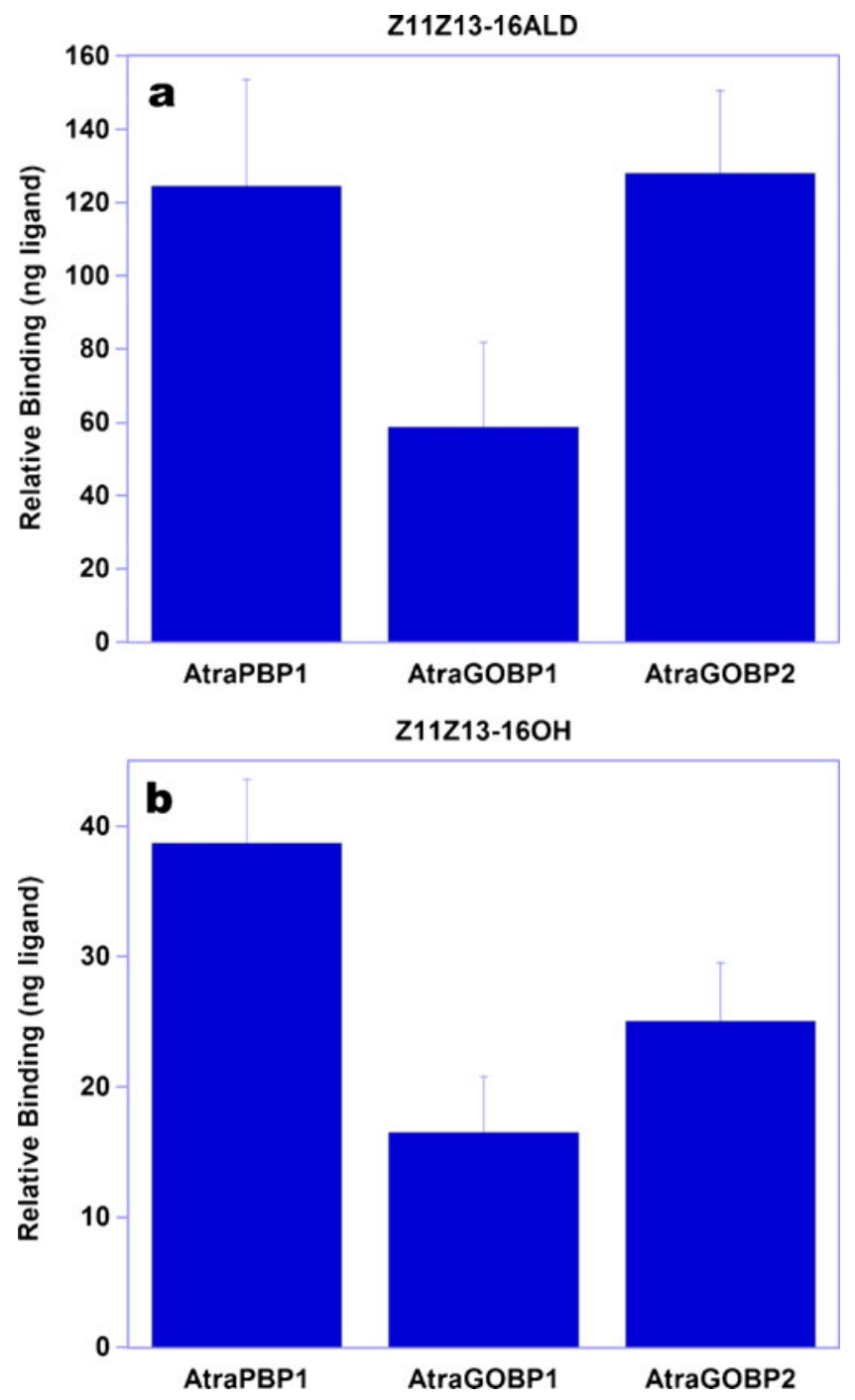

Fig. 6 Binding of the aldehyde and alcohol constituents of the Amyelois transitella sex pheromone system to male and female olfactory proteins. a test ligand, Z11Z13-16Ald and b test ligand, Z11Z13-16OH. The high affinity of the aldehyde to AtraPBP1 and AtraGOBP2 is comparable (a), whereas the alcohol showed higher affinity for AtraPBP1 than AtraGOBP2. AtraGOBP1 bound both aldehyde and alcohol with low but comparable affinity. Histogram bars represent mean+SEM $(N=5)$ 
The observation that both AtraGOBP1 and AtraGOBP2 were functional but do not bind known female attractants (Price et al. 1967) prompted us to test whether PAPE, IBAPE, and 1-phenylethanol indeed are detected by female antennae. EAG recordings from live moths showed that female antennae responded to these attractants as well as to nonanal in a dose-dependent manner (Fig. 3). With immobilized female moths we were able to record EAG response as high as $10 \mathrm{mV}$ at the highest dose tested (Fig. 3). During these measurements, we noticed a small change in EAG responses with the age of the test moth. Therefore, we determined the effect of age on EAG response to female attractants. Regardless of the dose $(0.1,1$, or $10 \mu \mathrm{g} / \mu \mathrm{l}$ source dose $)$ and the compound tested, female antennal responses decreased significantly at day-5 (Fig. 4). At lower doses, we noticed a reduced response from day-3 moths in a few cases, but the fact that the responses of day- 4 moths were always higher and that these discrepancies were not observed at a higher dose $(10 \mu \mathrm{g} / \mu \mathrm{l}$ source dose) suggests the variations at day-3 with lower doses are not physiologically significant.

We then compared the age dependence on EAG responses of male antennae by stimulating with constituents of the A. transitella sex pheromone system (Leal et al. 2005b). With both the major component of the femaleproduced sex pheromone, Z11Z13-16Ald, and another key component, Z3Z6Z9Z12Z15-23Hy, we observed a similar trend (Fig. 5). EAG responses to these pheromones recorded from male moth antennae were almost unchanged from day- 0 to day- 4 , with a significant decrease in day -5 , thus mirroring female response to female attractants. Overall EAG responses to Z11Z13-16Ald were $(\approx 4 \mathrm{x})$ higher than those to Z3Z6Z9Z12Z15-Hy at the same concentration, in part because of the lower volatility of the hydrocarbon compared to the smaller aldehyde. Male and female antennae responded with comparable intensity to Z11Z13-16Ald and 1-phenylethanol, respectively, tested at the same dose (compare Figs. $4 \mathrm{~b}$ and 5).

Finally, we tested whether AtraGOBP1 and/or AtraGOBP2 would bind and discriminate the aldehyde and alcohol constituents of the $A$. transitella sex pheromone as reported from a GOBP from B. mori (Zhou et al. 2009). Both AtraGOBP1 and AtraGOBP2 bound Z11Z13-16Ald

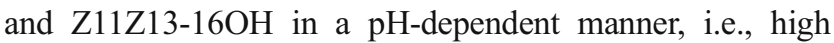
affinity at high $\mathrm{pH}$ and significantly lower (virtually no) binding affinity at low $\mathrm{pH}$. Interestingly, AtraGOBP2 bound to the main constituent of the sex pheromone with affinity equivalent to that of AtraPBP1 (Fig. 6a). The secondary constituent, Z11Z13-16OH, bound to AtraGOBP2 with smaller apparent affinity than to AtraPBP1 (Fig. 6b). On the other hand, AtraGOBP1 bound both Z11Z13-16Ald and Z11Z13-16OH, but with lower affinity than that observed for both AtraGOBP2 and AtraPBP1 (Fig. 6).
Taken together, these data suggest that reception of PAPE, IBAPE, and 1-phenylethanol might involve other OBPs than AtraGOBP1 and AtraGOBP2. Since we employed a protein-based approach for the isolation and cloning of olfactory proteins, we were able to identify only proteins expressed at high levels. Therefore, we cannot exclude that other OBPs are involved in the reception of these female attractants in $A$. transitella. The genome of $B$. mori, for example, showed a much higher OBP diversity than previously envisioned from isolated OBPs (Gong et al. 2009a). As indicated by EAG data, these attractants are indeed perceived by female antennae, but their transport to the receptors is not likely to be mediated by either AtraGOBP1 or AtraGOBP2. Interestingly, these proteins bound constituents of the sex pheromone, with the affinity of AtraGOBP2 to the main component being comparable to that of a pheromone-binding protein, AtraPBP1. Given the previous examples of GOBPs binding pheromone components in A. polyphemus and B. mori (Ziegelberger 1995; Zhou et al. 2009) and our data, it is tempting to suggest that these AtraGOBPs, particularly AtraGOBP2, are involved in pheromone reception. The larger number of pheromone constituents (Leal et al. 2005b) compared to the number of known PBPs (Leal et al. 2009) and the affinity of GOBPs for pheromones favor this hypothesis. However, evidence for the expression of GOBPs in pheromone-detecting sensilla and how reducing their expression by RNA interference (Pelletier et al. 2010) may affect pheromone reception remain exciting topics for future research.

Acknowledgments We are grateful to Bedoukian Research Inc. for providing samples of the constituents of the navel orangeworm sex pheromone; to Dr. Julien Pelletier for helpful comments on the manuscript; and to Dr. Brad Higbee (Paramount Farming) for providing moths and pistachios to reinvigorate and maintain our laboratory colony. Z.L. wishes to thank Professor Baozhen Hua (Northwest A \& F University, China) for his guidance during his Ph. D. studies. This work was supported in part by USDA-AFRI Grant 2009-05278, by the Almond Board of California, and by the California Pistachio Research Board. Z.L. (Northwest A \& F University, China) was supported by the Scholarship Council of China to conduct part of his Ph.D. studies in Davis and D.M.V. (Universidade Federal do Paraná, Curitiba, Brazil) received an undergraduate scholarship from Coordenação de Aperfeiçoamento de Pessoal de Nível Superior (CAPES) under a FIPSE-CAPES sponsored U.S.-Brazil Higher Education Consortium Program.

Open Access This article is distributed under the terms of the Creative Commons Attribution Noncommercial License which permits any noncommercial use, distribution, and reproduction in any medium, provided the original author(s) and source are credited.

\section{References}

BAn, L., ZhANG L., YAN Y., and Pelosi P. 2002. Binding properties of a locust's chemosensory protein. Biochem. Biophys. Res. Commun. 293:50-54. 
Beck, J. J., Merrill G. B., Higbee B. S., Light D. M., and Gee W. S. 2009. In situ seasonal study of the volatile production of almonds (Prunus dulcis) var. 'Nonpareil' and relationship to navel orangeworm. J. Agric. Food Chem. 57:3749-3753.

Biessmann, H., ANDRONopoulou E., BiesSMANn M. R., Douris V., Dimitratos S. D., Eliopoulos E., Guerin P. M., IATrou K., Justice R. W., Krober T., and others. 2010. The Anopheles gambiae odorant binding protein 1 (AgamOBP1) mediates indole recognition in the antennae of female mosquitoes. PLOS ONE 5: e9471.

Gong, D. P., Zhang H. J., Zhao P., Xia Q. Y., and Xiang Z. H. 2009a. The odorant binding protein gene family from the genome of silkworm, Bombyx mori. BMC Genomics 10:332.

Gong, Z. J., Zhou W. W., Yu H. Z., MaO C. G., Zhang C. X., Cheng J. A., and ZHU Z. R. 2009b. Cloning, expression and functional analysis of a general odorant-binding protein 2 gene of the rice striped stem borer, Chilo suppressalis (Walker) (Lepidoptera: Pyralidae). Insect Mol. Biol. 18:405-417.

JaCQuin-Joly, E., Bohbot J., Francois M. C., CAIN A. H., and NAGNAN-Le MeILlour P. 2000. Characterization of the general odorant-binding protein 2 in the molecular coding of odorants in Mamestra brassicae. Eur. J. Biochem. 267:6708-6714.

Laughlin, J. D., HA T. S., Jones D. N. M., and SMith D. P. 2008. Activation of pheromone-sensitive neurons is mediated by conformational activation of pheromone-binding protein. Cell 133:1255-1265

Leal, W. S., Chen A. M., Ishida Y., Chiang V. P., ERickson M. L., Morgan T. I., and TSURUdA J. M. 2005a. Kinetics and molecular properties of pheromone binding and release. Proc. Natl. Acad. Sci. USA 102:5386-5391.

Leal, W. S., Parra-Pedrazzoli A. L., Kaissling K.-E., Morgan T. I., Zalom F. G., PesaK D. J., Dundulis E. A., BurKs C. S., and HIGBEE B. S. 2005b. Unusual pheromone chemistry in the navel orangeworm: novel sex attractants and a behavioral antagonist. Naturwissenschaften 92:139-146.

Leal, W. S., Ishida Y., Pelletier J., Xu W., Rayo J., Xu X., and AMES J. B. 2009. Olfactory proteins mediating chemical communication in the navel orangeworm moth, Amyelois transitella. PLOS ONE 4:e7235.
NaKagawa, T., SaKurai T., Nishioka T., and Touhara K. 2005. Insect sex-pheromone signals mediated by specific combinations of olfactory receptors. Science 307:1638-1642.

PARRA-Pedrazzoli, A. L., and LeAL, W. S. 2006. Sexual behavior of the navel orangeworm, Amyelois transitella (Walker) (Lepidoptera: Pyralidae). Neotrop. Entomol. 35:769-774.

Pelletier, J., Guidolin A., Syed Z., Cornel A. J., and Leal, W. S. 2010. Knockdown of a mosquito odorant-binding protein involved in the sensitive detection of oviposition attractants. $J$. Chem. Ecol. 36:245-248.

Price, D. W., Mazrimas J. A., and Summers F. M. 1967. Chemical attractants for the navel orangeworm moths. Calif. Agric. 21:10-11.

Steinbrecht, R. A., LAUE M., and Ziegelberger G. 1995. Immunolocalization of pheromone-binding protein and general odorant-binding protein in olfactory sensilla of the silk moths Antheraea and Bombyx. Cell Tissue Res. 282:203-217.

Syed, Z., IshidA Y., TAYLOR K., Kimbrell D. A., and LEAL W. S. 2006. Pheromone reception in fruit flies expressing a moth's odorant receptor. Proc. Natl. Acad. Sci. USA 103:16538-16543.

Vogt, R. G., and RidDIFORD L. M. 1981. Pheromone binding and inactivation by moth antennae. Nature 293:161-163.

Vogt, R. G., Prestwich G. D., and Lerner M. R. 1991. Odorantbinding-protein subfamilies associate with distinct classes of olfactory receptor neurons in insects. J. Neurobiol. 22:74-84.

WoJTASEK, H., and LeAL W. S. 1999. Conformational change in the pheromone-binding protein from Bombyx mori induced by $\mathrm{pH}$ and by interaction with membranes. J. Biol. Chem. 274:30950-30956.

Xu, X., XU W., RaYo J., IShidA Y., LeAL W. S., and Ames J. B. 2010. NMR structure of navel orangeworm moth pheromone-binding protein (AtraPBP1): implications for $\mathrm{pH}$-sensitive pheromone detection. Biochemistry 49:1469-1476.

Zhou, J. J., Robertson G., He X., Dufour S., Hooper A. M., Pickett J. A., KeEP N. H., and Field L. M. 2009. Characterisation of Bombyx mori odorant-binding proteins reveals that a general odorant-binding protein discriminates between sex pheromone components. J. Mol. Biol. 389:529-545.

ZIEGELBERGER, G. 1995. Redox-shift of the pheromone-binding protein in the silkmoth Antheraea polyphemus. Eur. J. Biochem. 232:706-711. 